\title{
Improving medication safety and diabetes management in Hong Kong: a multidisciplinary approach
}

\author{
Agnes YS Chung, Shweta Anand, lan CK Wong, Kathryn CB Tan, Christine FF Wong, William CM Chui, \\ Esther W Chan *
}

\section{A B S T R A C T}

Introduction: Patients with diabetes often require complex medication regimens. The positive impact of pharmacists on improving diabetes management or its co-morbidities has been recognised worldwide. This study aimed to characterise drug-related problems among diabetic patients in Hong Kong and their clinical significance, and to explore the role of pharmacists in the multidisciplinary diabetes management team by evaluating the outcome of their clinical interventions.

Methods: An observational study was conducted at the Diabetes Clinic of a public hospital in Hong Kong from October 2012 to March 2014. Following weekly screening, and prior to the doctor's consultation, selected high-risk patients were interviewed by a pharmacist for medication reconciliation and review. Drug-related problems were identified and documented by the pharmacist who presented clinical recommendations to doctors to optimise a patient's drug regimen and resolve or prevent potential drug-related problems.

Results: A total of 522 patients were analysed and 417 drug-related problems were identified. The incidence of patients with drug-related problems was $62.8 \%$ with a mean of 0.9 (standard deviation, 0.6) drug-related problems per patient. The most common categories of drug-related problems were associated with dosing (43.9\%), drug choice (17.3\%), and non-allergic adverse reactions (15.6\%). Drugs

This article was published on $17 \mathrm{Mar}$ 2017 at www.hkmj.org. most frequently involved targeted the endocrine or cardiovascular system. The majority $(71.9 \%)$ of drug-related problems were of moderate clinical significance and $28.1 \%$ were considered minor problems. Drug-related problems were totally solved (50.1\%) and partially solved (11.0\%) by doctors' acceptance of pharmacist recommendations, or received acknowledgement from doctors (5.5\%).

Conclusions: Pharmacists, in collaboration with the multidisciplinary team, demonstrated a positive impact by identifying, resolving, and preventing drug-related problems in patients with diabetes. Further plans for sustaining pharmacy service in the Diabetes Clinic would enable further studies to explore the long-term impact of pharmacists in improving patients' clinical outcomes in diabetes management.

\section{Hong Kong Med J 2017;23:158-67}

DOI: $10.12809 / \mathrm{hkmj} 165014$

\section{AYS Chung, BPharm \\ ${ }^{1} S$ Anand, BDS \\ 2ICK Wong, PhD \\ ${ }^{3} \mathrm{KCB}$ Tan, $\mathrm{MD}, \mathrm{MBBCH}$ \\ ${ }^{4}$ CFF Wong, PharmD \\ ${ }^{4}$ WCM Chui, MSC \\ EW Chan *, PhD}

1 Department of Pharmacology and Pharmacy, Li Ka Shing Faculty of Medicine, The University of Hong Kong, Pokfulam, Hong Kong

2 Research Department of Practice and Policy, School of Pharmacy, University College London, United Kingdom

Department of Medicine, Queen Mary Hospital, Pokfulam, Hong Kong

${ }^{4}$ Department of Pharmacy, Queen Mary Hospital, Pokfulam, Hong Kong

* Corresponding author: ewchan@hku.hk

New knowledge added by this study

- Pharmacists make an important contribution to the identification, resolution, and prevention of drug-related problems by medication reconciliation and review. Most problems were related to dosing with moderate clinical significance according to Dean and Barber's validated scale for scoring medication errors. Over half of the clinical interventions initiated by pharmacists were accepted or acknowledged by doctors to improve medication management.

Implications for clinical practice or policy

Collaboration between pharmacists and other health care professionals is valuable for the improvement of medication safety in the management of diabetes.

\section{Introduction}

Diabetes mellitus is a chronic disease that is prevalent worldwide. ${ }^{1}$ Patients with diabetes often require complex medication regimens and are likely to develop multiple irreversible complications that significantly worsen their quality of life. ${ }^{2}$ Effective diabetes management requires collaboration among health care professionals in a multidisciplinary 
diabetes management team (DMT). Pharmacists, as a part of the DMT, are well positioned to optimise pharmacological treatment, educate patients about diabetes management, and promote medication compliance. ${ }^{3}$

The major role of a pharmacist in a DMT is to conduct medication reconciliation (MR) and medication review-MR is the process of comparing a patient's prescriptions with all their usual medications and identifying the most complete and updated medication histor $y^{4}$; whereas medication review aims to review a patient's medical and drug history, assess their current prescriptions, and ascertain their drug knowledge and compliance. ${ }^{5}$ This enables pharmacists to identify drug-related problems (DRPs) that can actually or potentially interfere with optimum health outcomes in specific patients. ${ }^{6,7}$ Polypharmacy (concurrent use of multiple medications) is commonly seen in people with chronic diseases which could lead to potential DRPs. ${ }^{8,9}$ These DRPs might be overlooked by prescribers and interfere with diabetes management. In several overseas studies, pharmacists have implemented timely interventions to resolve or prevent DRPs by offering recommendations to prescribers, with an acceptance rate of over $60 \% .{ }^{10-13}$

The positive impact of pharmacists in improving diabetes management or its co-morbidities has also been recognised by interventional and controlled observational studies worldwide. ${ }^{14}$ Greater overall improvement in glycosylated haemoglobin, fasting plasma glucose, blood pressure, cholesterol levels, renal outcomes, and medication adherence has been demonstrated in patients who received pharmacist-led diabetes services compared with the standard care. ${ }^{12,14-30}$ Few studies, however, have been conducted in Hong Kong. ${ }^{17,29}$ In view of inadequate available data and potential for expansion of local pharmacy services, more studies are required to investigate the future development of a sustainable diabetes service provided by pharmacists.

This study aimed to characterise DRPs among Chinese diabetic out-patients, and to define the clinical significance and outcome of pharmacist interventions; thereby highlighting their contribution to the detection, resolution, and prevention of DRPs to improve medication safety and diabetes management.

\section{Methods}

\section{Study design and setting}

An observational study was conducted weekly in the Diabetes Clinic at Queen Mary Hospital (QMH) from October 2012 to March 2014. The study protocol was approved by the Institutional Review Board of the University of Hong Kong (HKU)/ Hospital Authority (HA) Hong Kong West Cluster. Informed consent was not required for the study.

\section{通過跨學科方法改善用藥安全及糖尿病治療方案} 鍾欣璇、Shweta Anand、黃志基、陳俊明、黃方方、崔俊明、 陳慧賢

引言：糖尿病患者須經常服食多種藥物, 而藥劑師被公認為對改善糖 尿病治療方案或其併發症有正面影響。本研究旨在辨識香港糖尿病患 者的藥物相關的問題及其臨床重要性, 並透過評估臨床干預的成效, 探討藥劑師在跨學科糖尿病護理團隊中的角色。

方法：我們於 2012 年 10 月至 2014 年3月期間在香港一所公立醫院 的糖尿病診所內進行觀察性研究。研究期間, 藥劑師每週為經篩選 後的糖尿病高危患者在醫生診症前進行「藥物整合」（medication reconciliation ）和 $「$ 藥物復審」（medication review）。於辨識及記 錄與藥物相關的問題後, 向醫生提出臨床建議以優化患者的藥物治療 方案及解決或預防與潛在藥物相關的問題。

結果：被納入研究的522名患者中, 與藥物相關的問題共有 417 項, 發 生率為 $62.8 \%$ 。平均每名患者有 0.9 項（標準偏差，0.6項）與藥物相 關的問題。最常見的是與劑量有關的問題 $(43.9 \%)$ ，其次為藥物的 選擇 $(17.3 \%)$ 和非過敏性的不良反應（15.6\%），而最常涉及的為 內分泌或心血管科藥物。大多數 $(71.9 \%)$ 與藥物相關的問題具有中 度臨床重要性, 其餘 $28.1 \%$ 被認為屬輕微問題。醫生接受藥劑師建議 後有 $50.1 \%$ 的問題得以完全解決, 有 $11.0 \%$ 的問題得以部分解決, 而 $5.5 \%$ 的問題得到醫生確認。

結論：藥劑師與跨學科團隊合作, 通過問題識別、解決和預防糖尿病 患者的藥物相關的問題帶出正面影響。在糖尿病診所內繼續維持藥房 服務的計劃, 有助將來探討藥劑師對改善控制糖尿病治療方案的長遠 影響。

\section{Inclusion and exclusion criteria}

Patients were included if they were at 'high risk' due to their multiple disease state and complex drug regimen and if they fulfilled the following criteria:

- Aged $\geq 65$ years (elderly patients are considered having high risk for DRPs since they usually take more drugs than younger patients)

- Taking five or more medications including all routes of administration, or over-the-counter medications (regular or as needed)

- Taking medications that have a low therapeutic index or require monitoring

- Attending multiple specialist clinics

Nursing home residents were excluded due to their relatively low risk for non-compliance, compared with community-dwelling elderly patients.

\section{Procedure and materials}

The day before the scheduled weekly clinic consultation, two researchers screened the medical history, previous consultation notes, current medications, and latest laboratory results of Chinese elderly patients with diabetes to select high-risk patients. Selected patient records were printed and prepared for quick reference during the medication interview. To facilitate data collection, a memo was 
attached to the patient's records to indicate patient selection.

Two pharmacists from QMH and one from the HKU attended the clinic on alternate Wednesdays to compile a thorough medication history from selected patients and conduct an independent medication review prior to the medical consultation. During the review, pharmacists also recorded medications not shown in the Clinical Management System (CMS), such as drugs prescribed by general practitioners (GPs), over-the-counter products, vitamins, and herbal supplements.

A MR form (Appendix 1) was then completed by pharmacists, documenting the identified DRPs and formulating an intervention proposal. The MR forms were collected following medical consultation, either on the same day or within the next few days.

\section{Pharmacist intervention}

For the selected high-risk patients, pharmacists reviewed the patient's drug regimen and made recommendations to doctors for adjustment, provided doctors with an updated drug list after MR, suggested a need to further investigate a patient's condition, provided drug education to patients and caregivers, reinforced the importance of drug compliance to patients, and suggested lifestyle modifications such as dietary control.

Drug-related problems were identified from the completed MR forms, and pharmacist recommendations were collected for analysis. The CMS was checked for outcome of intervention.

\section{Data collection}

Demographic data-for example, age, gender, drug allergy status, number of regular medications obtained from the HA clinics, and the most current laboratory results, including glycosylated haemoglobin, fasting plasma glucose, and lipids (Appendix 2)-were retrieved from the CMS. Additional information in terms of medication, drug storage methods, smoking status, drinking habits, vaccination record, and latest readings from self-monitoring of blood glucose (SMBG) was also collected.

\section{Data analysis}

Demographic data were tabulated as frequency and percentage using Microsoft Excel 2010. Primary outcomes included the frequency and categories of DRPs, drug classes involved, clinical significance of DRPs, and outcome of pharmacist interventions. The incidence of DRPs was also calculated as the percentage of patients with at least one DRP.

\section{Definition and classification of drug-related problems}

Using the Pharmaceutical Care Network Europe
(PCNE) classification system for DRPs V5.01, DRPs were categorised as 'adverse reactions', 'drug choice problem,' 'dosing problem', 'drug use problem', 'interactions', or 'others.7 This is an established system that has been revised several times with tested validity and reproducibility ${ }^{11,31}$ and has been used in many studies. ${ }^{9,32,33}$ When a single drug was associated with more than one possible DRP category, the one that best described the clinical scenario was chosen. Drugs involved in DRPs were categorised according to their British National Formulary classification. ${ }^{34}$

The clinical significance of DRPs was assessed to determine their actual or potential consequence for patient health outcomes. Using a validated scale, ${ }^{35}$ four independent reviewers (two pharmacists and two doctors) scored the severity of each DRP from 0 (without potential effects on the patient) to 10 (lead to a fatal event). A mean score of $<3$ indicated a minor problem (very unlikely to cause adverse effects), 3 to 7 indicated a moderate problem (likely to cause some adverse effects or interfere with therapeutic goals), and $>7$ indicated a severe DRP that could likely cause death or lasting impairment.

To evaluate prescribers' acceptance level, the outcome of pharmacist interventions was categorised as 'not known', 'solved', 'partially solved', or 'not solved' according to PCNE classification V5.01.

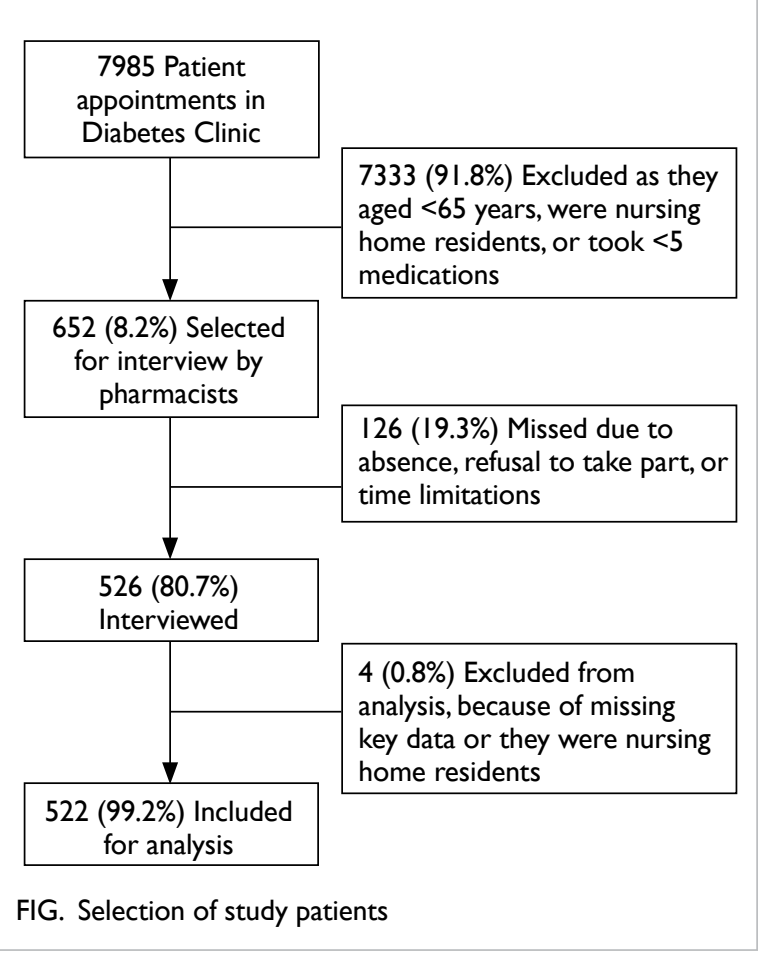


TABLE I. Demographics and characteristics of patients

\begin{tabular}{|c|c|}
\hline Demographics / characteristics & $\begin{array}{l}\text { No. }(\%) \text { of } \\
\text { patients§ }\end{array}$ \\
\hline Mean \pm SD (range) age (years) & $75.2 \pm 5.4(65-91)$ \\
\hline \multicolumn{2}{|l|}{ Gender } \\
\hline Female & $269(51.5)$ \\
\hline Male & $253(48.5)$ \\
\hline \multicolumn{2}{|l|}{ Drug allergy status } \\
\hline No known & $448(85.8)$ \\
\hline Known & $74(14.2)$ \\
\hline \multicolumn{2}{|l|}{$\begin{array}{l}\text { On medications or supplements other } \\
\text { than those prescribed by HA clinics }\end{array}$} \\
\hline Yes & $119(22.8)$ \\
\hline No & $403(77.2)$ \\
\hline \multicolumn{2}{|l|}{ Care provider in terms of medications } \\
\hline Self & $364(69.7)$ \\
\hline Family member & $80(15.3)$ \\
\hline Domestic helper & $26(5.0)$ \\
\hline Self and family & $20(3.8)$ \\
\hline Family and domestic helper & $5(1.0)$ \\
\hline Self and domestic helper & $3(0.6)$ \\
\hline Community nurses & $9(1.7)$ \\
\hline Not recorded & $15(2.9)$ \\
\hline \multicolumn{2}{|l|}{ Method of storing medications } \\
\hline $\mathrm{DAA}^{*}$ & $340(65.1)$ \\
\hline Original dispensing bag & $125(23.9)$ \\
\hline Others $†$ & $22(4.2)$ \\
\hline DAA and original dispensing bag & $6(1.1)$ \\
\hline DAA and others & $2(0.4)$ \\
\hline Original dispensing bag and others & $3(0.6)$ \\
\hline Not recorded & $24(4.6)$ \\
\hline \multicolumn{2}{|l|}{ Medications brought in with patient } \\
\hline None & $428(82.0)$ \\
\hline Some & $50(9.6)$ \\
\hline All & $14(2.7)$ \\
\hline Not recorded & $30(5.7)$ \\
\hline \multicolumn{2}{|l|}{ Medication list available on visit } \\
\hline Yes & $39(7.5)$ \\
\hline No & $431(82.6)$ \\
\hline Not recorded & $52(10.0)$ \\
\hline \multicolumn{2}{|l|}{ Smoking status } \\
\hline Non-smoker & $384(73.6)$ \\
\hline Ex-smoker & $100(19.2)$ \\
\hline Current smoker & $21(4.0)$ \\
\hline Not recorded & $17(3.3)$ \\
\hline
\end{tabular}

Abbreviations: DAA = dose administration aid; $\mathrm{HA}=$ Hospital Authority; SD = standard deviation; SMBG = self-monitoring of blood glucose

* Examples include pill boxes, monitored dosage systems, and patients' dispensing cabinets

+ Examples include film bottles and patients' plastic bags or containers

$\ddagger$ Patients who did not bring their records but recalled some readings were excluded from "yes"

$\S$ Because of rounding, not all percentages total 100
TABLE I. (cont'd)

\begin{tabular}{|lc|}
\hline Demographics / characteristics & $\begin{array}{c}\text { No. (\%) of } \\
\text { patients§ }\end{array}$ \\
\hline Drinking habit & \\
\hline Non-drinker & $465(89.1)$ \\
\hline Light drinker & $27(5.2)$ \\
\hline Moderate drinker & $2(0.4)$ \\
\hline Ex-drinker & $5(1.0)$ \\
\hline Not recorded & $23(4.4)$ \\
\hline Record of latest SMBG readings available & \\
\hline Yesł & $267(51.1)$ \\
\hline No or not recorded & $255(48.9)$ \\
\hline
\end{tabular}

Received pneumococcal vaccine within the past 5 years

\begin{tabular}{lr} 
Yes & $77(14.8)$ \\
No & $386(73.9)$ \\
\hline Not recorded or unsure & $59(11.3)$
\end{tabular}

Received influenza vaccine for current year

Yes $164(31.4)$

No $302(57.9)$

Not recorded 56 (10.7)

Received hepatitis B vaccine previously

Yes $8(1.5)$

No $\quad 434(83.1)$

Not recorded or unsure $\quad 80(15.3)$

Current smoker $21(4.0)$

Not recorded $17(3.3)$

\section{Results}

\section{Patient demographics and characteristics}

During the study period, a total of 652 patients were included based on the selection criteria; 526 (80.7\%) were interviewed, of whom $522(99.2 \%)$ were analysed (Fig).

The mean ( \pm standard deviation) age of the 522 patients was $75.2 \pm 5.4$ years (range, 65-91 years). The number of prescribed regular HA medications ranged from 5 to 17 with a mean of $9 \pm 2$. The demographics and characteristics of patients are shown in Table 1.

\section{Categories of drug-related problems}

A total of 417 DRPs were identified. Among the 522 patients analysed, $328(62.8 \%)$ had at least one DRP and the mean number of DRPs per patient was 0.9 \pm 0.6 . The most prevalent DRP category was related to dosing ( $\mathrm{n}=183,43.9 \%)$, followed by drug choice $(\mathrm{n}=72,17.3 \%)$ and non-allergic adverse reaction $(\mathrm{n}=65,15.6 \%)$. The subcategories of each of them are listed in Table 2. 
TABLE 2. Categories of drug-related problems (DRPs)

\begin{tabular}{|c|c|}
\hline Category & No. $(\%)$ of DRPs $(n=417)$ \\
\hline \multicolumn{2}{|l|}{ Adverse reactions } \\
\hline Side-effects suffered (non-allergic) & $65(15.6)$ \\
\hline Drug choice problem & $72(17.3)$ \\
\hline Inappropriate drug & $8(1.9)$ \\
\hline Inappropriate drug form & $2(0.5)$ \\
\hline Inappropriate duplication of therapeutic group or active ingredient & $18(4.3)$ \\
\hline Contra-indication for drug & $5(1.2)$ \\
\hline No clear indication for drug use & $4(1.0)$ \\
\hline No drug prescribed but clear indication & $35(8.4)$ \\
\hline Dosing problem & $183(43.9)$ \\
\hline Drug dose too low or dosage regimen insufficient & $97(23.3)$ \\
\hline Drug dose too high or dosage regimen too frequent & $69(16.5)$ \\
\hline Duration of treatment too long & $17(4.1)$ \\
\hline \multicolumn{2}{|l|}{ Drug use problem } \\
\hline Drug not taken / administered at all & $50(12.0)$ \\
\hline Interactions & $4(1.0)$ \\
\hline Potential interaction & $3(0.7)$ \\
\hline Manifest interaction & $1(0.2)$ \\
\hline Others & $43(10.3)$ \\
\hline Insufficient awareness of health and diseases (possibly leading to future problems) & $33(7.9)$ \\
\hline Inappropriate timing of administration & $2(0.5)$ \\
\hline Therapy failure & $1(0.2)$ \\
\hline Patient dissatisfied with therapeutic outcome despite taking drugs correctly & $7(1.7)$ \\
\hline
\end{tabular}

TABLE 3. Classes of medications involved in drug-related problems (DRPs)

\begin{tabular}{|c|c|c|}
\hline Class of medications & $\begin{array}{l}\text { No. }(\%) \text { of DRPs } \\
\text { involved }(n=417)\end{array}$ & Examples \\
\hline Cardiovascular system & $159(38.1)$ & $\begin{array}{l}\text { Aspirin, perindopril, losartan, valsartan, metoprolol tartrate, } \\
\text { atenolol, labetalol, simvastatin, atorvastatin, amlodipine, isosorbide } \\
\text { mononitrate, furosemide, hydrochlorothiazide, hydralazine, warfarin }\end{array}$ \\
\hline Endocrine system & $190(45.6)$ & \\
\hline Insulins & $133(31.9)$ & $\begin{array}{l}\text { Regular insulin, isophane insulin, biphasic isophane insulin, insulin } \\
\text { glargine }\end{array}$ \\
\hline Antidiabetic drugs & $56(13.4)$ & Metformin, gliclazide, sitagliptin \\
\hline Sex hormones & $1(0.2)$ & Finasteride \\
\hline Nutrition and blood & $21(5.0)$ & Calcium carbonate, potassium chloride, darbepoetin alfa injection \\
\hline Gastrointestinal system & $14(3.4)$ & Pantoprazole, rabeprazole, famotidine, digestive enzymes \\
\hline Obstetrics, gynaecology and urinary tract disorders & $6(1.4)$ & Prazosin, terazosin, doxazosin \\
\hline Respiratory system & $5(1.2)$ & Theophylline, ipratropium, salbutamol, beclomethasone, loratadine \\
\hline Malignant disease and immunosuppression & $3(0.7)$ & Azathioprine, prednisolone \\
\hline Central nervous system & $3(0.7)$ & Gabapentin, pregabalin, tramadol \\
\hline Infections & $1(0.2)$ & Isoniazid and rifampicin \\
\hline Musculoskeletal and joint diseases & $5(1.2)$ & Allopurinol, colchicine \\
\hline Skin & $1(0.2)$ & Fluocinolone acetonide cream \\
\hline Others & $1(0.2)$ & Peritoneal dialysis fluid \\
\hline Multiple drugs ${ }^{\star}$ & $8(1.9)$ & - \\
\hline
\end{tabular}

* In most cases, DRPs were related to poor drug compliance by the patient 


\section{Classes of medications involved in drug- related problems}

The most common classes of medication involved were those targeting the endocrine system with 190 (45.6\%) DRPs, followed by cardiovascular system with 159 (38.1\%) DRPs (Table 3).

\section{Clinical significance of drug-related problems}

The mean clinical severity scores assigned to DRPs ranged from 0.50 to 7.00 . The majority of DRPs $(n=300,71.9 \%)$ were classified as moderate with the remainder $(n=117,28.1 \%)$ considered minor. No clinically severe DRP was identified (Table 4).

\section{Outcome of pharmacist interventions}

As Table 5 shows, modifying drug regimens or reinforcing compliance by doctors or referral to

TABLE 4. Clinical severity scores assigned to drug-related problems (DRPs)

\begin{tabular}{|c|c|c|}
\hline Severity & Mean score & No. $(\%)$ of DRPs $(n=417)$ \\
\hline \multirow[t]{10}{*}{ Minor } & 0.50 & $1(0.2)$ \\
\hline & 1.00 & $12(2.9)$ \\
\hline & 1.25 & $2(0.5)$ \\
\hline & 1.50 & $10(2.4)$ \\
\hline & 1.75 & $4(1.0)$ \\
\hline & 2.00 & $33(7.9)$ \\
\hline & 2.25 & $7(1.7)$ \\
\hline & 2.50 & $30(7.2)$ \\
\hline & 2.75 & $18(4.3)$ \\
\hline & Subtotal & $117(28.1)$ \\
\hline \multirow[t]{17}{*}{ Moderate } & 3.00 & $45(10.8)$ \\
\hline & 3.25 & $22(5.3)$ \\
\hline & 3.50 & $29(7.0)$ \\
\hline & 3.75 & $16(3.8)$ \\
\hline & 4.00 & $65(15.6)$ \\
\hline & 4.25 & $8(1.9)$ \\
\hline & 4.50 & $27(6.5)$ \\
\hline & 4.75 & $7(1.7)$ \\
\hline & 5.00 & $42(10.1)$ \\
\hline & 5.25 & $5(1.2)$ \\
\hline & 5.50 & $11(2.6)$ \\
\hline & 5.75 & $2(0.5)$ \\
\hline & 6.00 & $15(3.6)$ \\
\hline & 6.50 & $1(0.2)$ \\
\hline & 6.75 & $1(0.2)$ \\
\hline & 7.00 & $4(1.0)$ \\
\hline & Subtotal & 300 (71.9) \\
\hline
\end{tabular}

pharmacists solved 209 (50.1\%) DRPs. On the other hand, 46 (11.0\%) DRPs were partially resolved by doctors adjusting prescriptions, although not according to pharmacist recommendations; 62 (14.9\%) DRPs were not resolved due to patient reluctance to change prescriptions, resolution considered unnecessary, or for unknown reasons; 23 (5.5\%) DRPs had an unknown outcome because these were non-compliance issues not acknowledged by doctors.

\section{Discussion}

The incidence of patients with DRPs (62.8\%) and the mean number of DRPs per patient analysed (0.9) in this study were comparable to a Norwegian study $(59.2 \% \text { and } 1.2 \text {, respectively })^{10}$ but considerably lower than those identified in four overseas studies (incidence of $80.7 \%-90.5 \%$, and mean number of DRPs per patient between $1.9 \pm 1.2$ and $4.6 \pm$ 1.7). ${ }^{9,11,12,36}$ Such discrepancies might be attributed to variations in patient selection criteria, data collection methods, pharmacists' clinical experience, as well as study duration and setting. ${ }^{9,36,37}$

The majority of DRPs were dosing problems (43.9\%), with "drug dose too low or dosage regimen insufficient" as the largest subcategory. In contrast to the lower percentage (5.9\%-21.6\%) in five overseas studies, ${ }^{9-12,36}$ our high prevalence of dosing problems was in line with a local study of medication incidents among hospital in-patients, ${ }^{38}$ mostly arising from self-adjustment of dosage or frequency, confusion about previous dose changes and dosage modification by GPs or doctors overseas. These highlight the pivotal role of local pharmacists in conducting MR, reviewing drug dosages to ensure safety and efficacy, monitoring patients' metabolic control regularly as well as reminding patients and/or their caregivers to maintain an updated medication list and follow the latest drug label instructions.

Drug choice problem was the second most common DRP; $17.3 \%$ of DRPs related to this category, which is comparable to the findings of two overseas studies $(9.1 \%, 23 \%)^{9,36}$ but deviating from others (31.8\%-30.2\%). ${ }^{10,11}$ The most common subcategory was "no drug prescribed but clear indication", such as the omission of angiotensin-converting enzyme inhibitor/angiotensin-receptor blocker (ACEI/ $\mathrm{ARB}$ ) in patients with microalbuminuria or patient's reluctance to use insulin. Hence, pharmacists have a role in advising doctors to adhere to the latest treatment guidelines and educate patients about the treatment benefits of each drug class. ${ }^{39}$ Other causes of problems surrounding drug choice included drug duplication and changes to drug choices by GPs to prevent side-effects. This suggests that some DRPs might have arisen due to the lack of a common platform between the public and private health care sector for sharing patient information. Pharmacists 
TABLE 5. Outcome of pharmacist interventions

\begin{tabular}{|c|c|c|}
\hline Outcome & $\begin{array}{l}\text { No. }(\%) \text { of DRP } \\
(n=417)\end{array}$ & Examples \\
\hline Problem totally solved & $209(50.1)$ & $\begin{array}{l}\text { A patient on perindopril, whose dose was increased in the nephrology clinic at last follow-up, } \\
\text { presented with hyperkalaemia (serum potassium level, } 5.7 \mathrm{mmol} / \mathrm{L}) \text {. Pharmacist suspected the cause } \\
\text { as the side-effect of ACEI. Physician agreed to cease drug until next follow-up in nephrology clinic }\end{array}$ \\
\hline Problem partially solved & $46(11.0)$ & $\begin{array}{l}\text { A patient was prescribed with the following antidiabetic drugs by GP: metformin } 500 \mathrm{mg} \text { BD, sitagliptin } \\
50 \mathrm{mg} \text { OD, and glimepiride } 1 \mathrm{mg} \text { OD. In view of patient's renal function (serum creatinine increased } \\
\text { from } 193 \mu \mathrm{mol} / \mathrm{L} \text { to } 213 \mu \mathrm{mol} / \mathrm{L} \text { ), pharmacist suggested stopping metformin and changing sitagliptin } \\
\text { to linagliptin. Physician noted "strongly advised to stop metformin" in CMS, but made no comment on } \\
\text { changing sitagliptin }\end{array}$ \\
\hline Not solved & $62(14.9)$ & \\
\hline $\begin{array}{l}\text { Lack of cooperation of } \\
\text { patient }\end{array}$ & $5(1.2)$ & $\begin{array}{l}\text { A T2DM patient had good compliance with four oral antidiabetic drugs (metformin } 1500 \mathrm{mg} \text { BD, } \\
\text { gliclazide } 160 \mathrm{mg} \text { BD, sitagliptin } 100 \mathrm{mg} \text { daily, and acarbose } 50 \mathrm{mg} \text { TDS). The pharmacist explained } \\
\text { that the maximum doses of most drugs had already been reached, but the patient still refused } \\
\text { admission, insulin therapy, or any additional medications. His latest HbA1c was } 12.6 \% \text { and FPG was } \\
19.6 \mathrm{mmol} / \mathrm{L} \text {. The doctor recorded the problem in CMS, explained health risks and advised patient to } \\
\text { attend emergency department if he felt unwell }\end{array}$ \\
\hline $\begin{array}{l}\text { No need or impossible } \\
\text { to solve problem }\end{array}$ & $35(8.4)$ & $\begin{array}{l}\text { The pharmacist recorded that a patient would discuss with the doctor in orthopaedics clinic regarding } \\
\text { calcium carbonate } 1000 \mathrm{mg} \text { daily due to constipation. The doctor in Diabetes Clinic did not record the } \\
\text { problem in CMS and kept the current dosage }\end{array}$ \\
\hline For unknown reasons & $22(5.3)$ & $\begin{array}{l}\text { Furosemide dosage prescribed in cardiology clinic was increased from } 20 \mathrm{mg} \text { BD to } 40 \mathrm{mg} \text { mane and } \\
20 \mathrm{mg} \text { nocte by GP due to oedema. The doctor in Diabetes Clinic neither made a record nor changed } \\
\text { the prescription }\end{array}$ \\
\hline Unknown & 77 (18.5) & $\begin{array}{l}\text { A patient took sitagliptin } 50 \mathrm{mg} \text { instead of } 100 \mathrm{mg} \text { daily claiming that doctor told her half a tablet } \\
\text { would be enough. Pharmacist asked the doctor to review but no record was made in CMS and doctor } \\
\text { continued prescribing } 100 \mathrm{mg} \text { daily }\end{array}$ \\
\hline $\begin{array}{l}\text { Others (acknowledged } \\
\text { by doctor, but no action } \\
\text { taken) }\end{array}$ & $23(5.5)$ & $\begin{array}{l}\text { A patient who had coronary artery disease, self-adjusted the dosage of metoprolol tartrate from } 25 \mathrm{mg} \\
\text { BD to } 25 \mathrm{mg} \text { daily. The doctor recorded the problem but did not prescribe the drug (for follow-up in } \\
\text { cardiology clinic) }\end{array}$ \\
\hline
\end{tabular}

Abbreviations: $\mathrm{ACEI}=$ angiotensin-converting enzyme inhibitor; $\mathrm{BD}=$ twice daily; CMS = Clinical Management System; DRP = drug-related problems;

FPG = fasting plasma glucose; $\mathrm{GP}=$ general practitioner; $\mathrm{HbAlc}=$ glycosylated haemoglobin; mane = every morning; nocte = every night; $\mathrm{OD}=$ once daily; T2DM = type 2 diabetes mellitus; TDS = three times daily

can make a valuable contribution by establishing a patient's drug history by MR and by liaison with different health care sectors.

Adverse reactions were the third most common DRP (15.6\%). The major types of "sideeffects suffered (non-allergic)" were insulin-induced hypoglycaemia, gastrointestinal disturbances, and dizziness caused by antidiabetic drugs, for which pharmacists recommended changes in drug choice or dosage. Adverse reactions could lead to other DRP categories, ${ }^{7}$ such as drug choice and drug use problems. This reflects the pharmacist's pivotal role in reviewing prescribed doses, suggesting dosage adjustments to doctors, monitoring adverse effects, and providing information about prevention of side-effects (such as performing SMBG regularly to prevent hypoglycaemia). ${ }^{39}$

Drug use issues were the fourth most common category with comparable prevalence $(12.0 \%)$ with a Malaysian study ${ }^{9}$ although this ranges widely among other studies (3.8\%-54.2\%). ${ }^{10,11,36}$ Reasons for the subcategory of "drug not taken/administered at all" included inability to purchase a self-financed item due to cost, ignorance of the indications, concern about side-effects, and confusion about previous regimen changes. ${ }^{40}$ In our study, pharmacists mainly intervened by direct patient counselling, recommending reinforcement of patient compliance to doctors or suggesting changes to drug regimens. Pharmacists could also work closely with other DMT members to educate patients about their disease and the most updated regimen, address drug cost concerns or side-effects, and encourage patients to update their medication list and use dose administration aids such as pill boxes. ${ }^{41}$

The low prevalence of drug interactions $(1.0 \%)$ was similar to that $(0.6 \%)$ in a Danish study, ${ }^{36}$ although much higher percentages were found in three other studies $(8.0 \%-16.3 \%),{ }^{9-11}$ possibly ascribed to differences in prescribing practice, references used to define drug interactions, ${ }^{9}$ and also because CMS could already detect a range of clinically significant interactions when doctors issued prescriptions. Nonetheless system checking and prompts cannot replace clinical judgement or recommendations of alternative regimens. Other categories of DRPs included "insufficient awareness of health and diseases" (such as poor dietary control) 
and "inappropriate timing of administration", but this category could also encompass therapy failure and inappropriate lifestyle choices, resulting in greater variation of prevalence from overseas studies $(6.8 \%-46.6 \%) .^{9-11,36}$ Pharmacists are ideally positioned to advise patients about the importance of diet, smoking cessation, regular exercise, and SMBG. ${ }^{22}$

The drug classes most implicated in DRPs were for the endocrine system (45.6\%) followed by cardiovascular system (38.1\%). These findings were not surprising as insulins, oral antidiabetic drugs, antihypertensive, antihyperlipidaemic, antiplatelet agents, and ACEI/ARB are most commonly prescribed to manage diabetes, its co-morbidities and complications. ${ }^{11,39}$

The majority of DRPs were classified as moderate. Among similar overseas studies, only one analysed the clinical significance of DRPs, in which $87 \%$ had high or medium clinical/practical relevance. ${ }^{10}$ These findings could not be readily compared with the present study because of different assessment scales, potential variations in reviewers' clinical experience, ${ }^{35}$ and unknown relative proportions of cases with medium and high relevance.

Over half of the DRPs were totally solved as doctors implemented pharmacist recommendations. The acceptance rate was somewhat similar to that observed in two overseas studies (60.2\%-62.7\%). ${ }^{12,13}$ The physicians acknowledged the provision of service by pharmacists and were more aware of the written recommendations provided by pharmacists. In particular, the value of verbal communication between different health care professionals in resolving or preventing DRPs has been recognised in earlier studies, ${ }^{10,42-45}$ suggesting potential improvement in the acceptance rate if pharmacists had more time to hand over DRPs by speaking with doctors.

The outcome of pharmacist interventions could also be influenced by doctors' clinical experience and familiarity with the new service. Doctors' acceptance level could have been underestimated since some of them might have neglected or missed written information from pharmacists. This highlights the importance of promoting the role of pharmacists to doctors and keeping all participating doctors wellinformed.

\section{Difficulties and limitations}

This pilot study allowed for an opportunity to assess the proportion of patients who might be seen by clinical pharmacists in a busy specialist out-patient clinic at a teaching hospital. Approximately $10 \%$ of patients were chosen each week and not all eligible patients could be selected owing to time restrictions. The number of patients interviewed was further limited due to time constraints, patient absence or refusal. Local figures from the QMH Diabetes Clinic indicate that approximately $7 \%$ to $8 \%$ of all patients who attend the clinic are deemed 'high risk', based on ongoing work and prioritisation of those taking five or more regular medications. Limited work space was another consideration. A designated area is required to conduct patient interviews. Further arrangements could be made with the medical and nursing staff in the Diabetes Clinic to access better space.

This study only described the current situation of DRPs. It did not assess the implementation of interventions and their impact on patient health outcome. As the majority of patients did not bring their drugs to the clinic and had no medication list available, the MR process was not always comprehensive or effective. Only a minority of patients could name their regular drugs. The majority relied on pharmacist investigation and prompts about the colour, shape, package, or indication of each drug. Due to the potential for misinterpretation, DRP prevalence may be underestimated. One possible solution might be to show patients samples of commonly prescribed medications. Alternatively, selected patients could be telephoned in advance and asked to bring along their medications, although this measure may not be sustainable. A multifaceted promotional campaign could be introduced to encourage patients to bring their regular medications to clinic. This has been shown to be effective in an emergency setting. ${ }^{46}$

Although completed MR forms were presented to doctors after the interviews, some written information might have been missed with a consequent lack of response to certain DRPs. Pharmacists should ideally have informed doctors about every DRP in person, but this was not always possible due to time constraints and the great volume of patients. In the long run, pharmacists should document DRPs and their recommendations in the CMS. This would enhance visibility and allow doctors to input their response electronically and facilitate organised documentation and easy data retrieval.

\section{Future directions}

Upon completion of this study, pharmacists have been continuing to provide $\mathrm{MR}$ and medication review services in QMH Diabetes Clinic. They have also been collecting data about DRPs to plan for a sustainable service. Following a longer study period, patient and staff satisfaction surveys could be introduced and also control groups added to enable comparison of the effectiveness of pharmacist intervention. This would further support the extension of hours of service and potentially the setup of similar pharmacy services to other hospitals and diabetes clinics in Hong Kong. 


\section{Conclusions}

Approximately two thirds of patients at the Diabetes Clinic had at least one DRP. The most frequent categories of DRPs were related to dosing, drug choice, and non-allergic adverse reaction. Drugs targeting the endocrine and cardiovascular systems were most commonly involved. The majority of DRPs were of moderate clinical significance. Pharmacist interventions for over half the DRPs were accepted or acknowledged by prescribers. Through effective communication and collaboration within the multidisciplinary health care team, pharmacists had a positive impact on identifying, resolving, and preventing DRPs. Future plans to sustain the diabetes service will enable more local research to enhance medication safety and optimise patients' medication regimens in diabetes management.

\section{Appendices}

Additional material related to this article can be found on the HKMJ website. Please go to <http:// www.hkmj.org>, and search for the article.

\section{Acknowledgements}

We would like to acknowledge Ms Cyan Chan for her assistance in patient screening and data collection, and pharmacists Ms Phoebe Chan (HKU); Ms Amy Chan, Ms Dominique Yeung, Ms Katie Chan, and Mr Ric Fung (QMH); Prof Karen Lam (QMH); nursing and medical staff in S6 Diabetes Clinic, QMH for their advice and contributions to service provision in the study. We would also like to thank Mr Michael Ling and Ms Elaine Lo (Kwong Wah Hospital); Dr Michael Mok (Geelong Hospital, Victoria, Australia); Dr Vickie Tse (HKU) contributing to the independent assessment of clinical severity of DRPs; and Dr Anthony Tam (HKU) and Sharon Law (HKU) for proofreading the manuscript.

\section{References}

1. International Diabetes Federation International diabetes atlas. 6th ed. Available from: http://www.diabetesatlas.org/ resources/previous-editions.html. Accessed Mar 2014.

2. Fowler MJ. Microvascular and macrovascular complications of diabetes. Clin Diabetes 2008;26:77-82.

3. Tapp H, Phillips SE, Waxman D, Alexander M, Brown R, Hall M. Multidisciplinary team approach to improved chronic care management for diabetic patients in an urban safety net ambulatory care clinic. J Am Board Fam Med 2012;25:245-6.

4. Hellström LM, Bondesson Å, Höglund P, Eriksson T. Errors in medication history at hospital admission: prevalence and predicting factors. BMC Clin Pharmacol 2012;12:9.

5. Krska J, Cromarty JA, Arris F, et al. Pharmacist-led medication review in patients over 65: a randomized, controlled trial in primary care. Age Ageing 2001;30:20511.
6. Draft statement on pharmaceutical care. ASHP Council on Professional affairs. American Society of Hospital Pharmacists. Am J Hosp Pharm 1993;50:126-8.

7. Pharmaceutical Care Network Europe. The PCNE Classification V 5.01. 2006. Available from: http://www. pcne.org/upload/files/16_PCNE_classification_V5.01.pdf. Accessed 22 Oct 2013.

8. Viktil KK, Blix HS, Moger TA, Reikvam A. Polypharmacy as commonly defined is an indicator of limited value in the assessment of drug-related problems. Br J Clin Pharmacol 2007;63:187-95.

9. Zaman Huri H, Fun Wee H. Drug related problems in type 2 diabetes patients with hypertension: a cross-sectional retrospective study. BMC Endocr Disord 2013;13:2.

10. Granas AG, Berg C, Hjellvik V, et al. Evaluating categorisation and clinical relevance of drug-related problems in medication reviews. Pharm World Sci 2010;32:394-403.

11. van Roozendaal BW, Krass I. Development of an evidencebased checklist for the detection of drug related problems in type 2 diabetes. Pharm World Sci 2009;31:580-95.

12. Borges AP, Guidoni CM, Ferreira LD, de Freitas O, Pereira LR. The pharmaceutical care of patients with type 2 diabetes mellitus. Pharm World Sci 2010;32:730-6.

13. DeName B, Divine H, Nicholas A, Steinke DT, Johnson CL. Identification of medication-related problems and health care provider acceptance of pharmacist recommendations in the DiabetesCARE program. J Am Pharm Assoc 2008;48:731-6.

14. Kiel PJ, McCord AD. Pharmacist impact on clinical outcomes in a diabetes disease management program via collaborative practice. Ann Pharmacother 2005;39:182832 .

15. Wubben DP, Vivian EM. Effects of pharmacist outpatient interventions on adults with diabetes mellitus: a systematic review. Pharmacotherapy 2008;28:421-36.

16. Evans CD, Watson E, Eurich DT, et al. Diabetes and cardiovascular disease interventions by community pharmacists: a systematic review. Ann Pharmacother 2011;45:615-28.

17. Chan CW, Siu SC, Wong CK, Lee VW. A pharmacist care program: positive impact on cardiac risk in patients with type 2 diabetes. J Cardiovasc Pharmacol Ther 2012;17:5764.

18. Pepper MJ, Mallory N, Coker TN, Chaki A, Sando KR. Pharmacists' impact on improving outcomes in patients with type 2 diabetes mellitus. Diabetes Educ 2012;38:40916.

19. Jarab AS, Alqudah SG, Mukattash TL, Shattat G, AlQirim T. Randomized controlled trial of clinical pharmacy management of patients with type 2 diabetes in an outpatient diabetes clinic in Jordan. J Manag Care Pharm 2012;18:516-26.

20. Jacobs M, Sherry PS, Taylor LM, Amato M, Tataronis GR, Cushing G. Pharmacist Assisted Medication Program Enhancing the Regulation of Diabetes (PAMPERED) study. J Am Pharm Assoc 2012;52:613-21.

21. Ali M, Schifano F, Robinson P, et al. Impact of community pharmacy diabetes monitoring and education programme on diabetes management: a randomized controlled study. Diabet Med 2012;29:e326-33.

22. Al Mazroui NR, Kamal MM, Ghabash NM, Yacout TA, Kole PL, McElnay JC. Influence of pharmaceutical care on 
health outcomes in patients with type 2 diabetes mellitus. Br J Clin Pharmacol 2009;67:547-57.

23. Mehuys E, Van Bortel L, De Bolle L, et al. Effectiveness of a community pharmacist intervention in diabetes care: a randomized controlled trial. J Clin Pharm Ther 2011;36:602-13.

24. Shah M, Norwood CA, Farias S, Ibrahim S, Chong PH, Fogelfeld L. Diabetes transitional care from inpatient to outpatient setting: pharmacist discharge counseling. J Pharm Pract 2013;26:120-4.

25. Heisler M, Hofer TP, Schmittdiel JA, et al. Improving blood pressure control through a clinical pharmacist outreach program in patients with diabetes mellitus in 2 high-performing health systems: the adherence and intensification of medications cluster randomized, controlled pragmatic trial. Circulation 2012;125:2863-72.

26. Dobesh PP. Managing hypertension in patients with type 2 diabetes mellitus. Am J Health Syst Pharm 2006;63:1140-9.

27. Planas LG, Crosby KM, Mitchell KD, Farmer KC. Evaluation of a hypertension medication therapy management program in patients with diabetes. J Am Pharm Assoc 2009;49:164-70.

28. Leal S, Soto M. Chronic kidney disease risk reduction in a Hispanic population through pharmacist-based diseasestate management. Adv Chronic Kidney Dis 2008;15:1627.

29. Leung WY, So WY, Tong PC, Chan NN, Chan JC. Effects of structured care by a pharmacist-diabetes specialist team in patients with type 2 diabetic nephropathy. Am J Med 2005;118:1414.

30. American Pharmacists Association. DOTx. MED: Pharmacist-delivered interventions to improve care for patients with diabetes. J Am Pharm Assoc 2012;52:25-33.

31. Björkman IK, Sanner MA, Bernsten CB. Comparing 4 classification systems for drug-related problems: processes and functions. Res Social Adm Pharm 2008;4:320-31.

32. Eichenberger PM, Lampert ML, Kahmann IV, van Mil JW, Hersberger KE. Classification of drug-related problems with new prescriptions using a modified PCNE classification system. Pharm World Sci 2010;32:362-72.

33. Hohmann C, Eickhoff C, Klotz JM, Schulz M, Radziwill R. Development of a classification system for drug-related problems in the hospital setting (APS-Doc) and assessment of the inter-rater reliability. J Clin Pharm Ther 2012;37:27681.

34. British Medical Association, Royal Pharmaceutical Society of Great Britain. British National Formulary 71. London: British Medical Association, Royal Pharmaceutical Society; 2016.

35. Dean BS, Barber ND. A validated, reliable method of scoring the severity of medication errors. Am J Health Syst Pharm 1999;56:57-62.

36. Haugbølle LS, Sørensen EW. Drug-related problems in patients with angina pectoris, type 2 diabetes and asthma-interviewing patients at home. Pharm World Sci 2006;28:239-47.

37. Westerlund $\mathrm{T}$, Almarsdottir AB, Melander A. Factors influencing the detection rate of drug-related problems in community pharmacy. Pharm World Sci 1999;21:245-50.

38. Song L, Chui WC, Lau CP, Cheung BM. A 3-year study of medication incidents in an acute general hospital. J Clin Pharm Ther 2008;33:109-14.

39. American Diabetes Association. Standards of medical care in diabetes-2013. Diabetes Care 2013;36 Suppl 1:S11-66.

40. Odegard PS, Gray SL. Barriers to medication adherence in poorly controlled diabetes mellitus. Diabetes Educ 2008;34:692-7.

41. Morello CM, Chynoweth M, Kim H, Singh RF, Hirsch JD. Strategies to improve medication adherence reported by diabetes patients and caregivers: results of a taking control of your diabetes survey. Ann Pharmacother 2011;45:14553.

42. Perera PN, Guy MC, Sweaney AM, Boesen KP. Evaluation of prescriber responses to pharmacist recommendations communicated by fax in a medication therapy management program (MTMP). J Manag Care Pharm 2011;17:345-54.

43. Doucette WR, McDonough RP, Klepser D, McCarthy R. Comprehensive medication therapy management: identifying and resolving drug-related issues in a community pharmacy. Clin Ther 2005;27:1104-11.

44. Chrischilles EA, Carter BL, Lund BC, et al. Evaluation of the Iowa Medicaid pharmaceutical case management program. J Am Pharm Assoc 2004;44:337-49.

45. Galt KA. Cost avoidance, acceptance, and outcomes associated with a pharmacotherapy consult clinic in a Veterans Affairs Medical Center. Pharmacotherapy 1998;18:1103-11.

46. Chan EW, Taylor SE, Marriott JL, Barger B. Bringing patients' own medications into an emergency department by ambulance: effect on prescribing accuracy when these patients are admitted to hospital. Med J Aust 2009;191:3747. 